\title{
Supplier Selection and Evaluation of Fresh Supermarket Based on AHP
}

\author{
Mian Fu' ${ }^{1}$, Dan dan Wang ${ }^{1}$ \\ ${ }^{1}$ Business School, Xinhua University of Anhui Province, Hefei, China
}

\begin{abstract}
With the change of consumption concept, fresh food is the necessity of people's life. The main value of fresh food is reflected in the freshness of products and the reliability of consumption. The selection and evaluation of suppliers of fresh food is the primary problem that fresh supermarket enterprises need to consider at present. Taking fresh supermarket supplier selection as the research object, this paper analyzes the key influencing factors of fresh supermarket enterprise supplier selection and evaluation, and constructs a fresh supermarket enterprise supplier selection and evaluation index system with 4 first level indicators and 15 second level indicators. At the same time, using the analytic hierarchy process and fuzzy evaluation method, this paper analyzes the evaluation index system of fresh legend supermarket in Hefei city of Anhui Province. According to the evaluation results, suppliers need to increase the rapid response capacity and improve the cold chain logistics facilities and equipment.
\end{abstract}

\section{INTRODUCTION}

Food is the first priority of the people. With the change of consumption concept, fresh food is the necessities of people's life. The main value of fresh food is reflected in the freshness of products and the reliability of consumption. Therefore, in order to ensure the freshness of fresh products, we must shorten the circulation link. As the preferred place for consumers to buy fresh food, the competition between fresh supermarket enterprises is becoming increasingly fierce, and even has evolved into the competition between supply chains. Therefore, the selection and evaluation of suppliers of fresh food is the primary problem for fresh supermarket enterprises to consider $[1,2]$.

\section{THE CONSTRUCTION OF EVALUATION INDEX SYSTEM FOR FRESH SUPERMARKET SUPPLIER SELECTION}

\subsection{Basic Principles of Constructing Evaluation Index System}

The establishment of a reasonable index system is the basic premise for the objective evaluation of fresh supermarket suppliers. In the process of selecting evaluation indexes, we need to fully consider the characteristics of fresh agricultural products to evaluate the supplier selection of fresh supermarket more accurately and comprehensively. The specific principles are as follows:

(1) Principle of pertinence

The purpose of this paper is to find out the key factors that affect the service ability of fresh supermarket by analyzing the evaluation results of suppliers, so as to provide the decision basis for the fresh supermarket to choose suppliers.

(2) Principle of combination of qualitative and quantitative

In order to ensure the rationality and effectiveness of supplier selection evaluation in fresh supermarket, we should not use qualitative or quantitative indicators alone, but we need to combine qualitative and quantitative indicators to reflect the service ability of suppliers comprehensively and accurately. At the same time, in order to make the evaluation carry out smoothly, the selected qualitative indicators are also better to be easily quantified.

(3) Operability principle

When selecting evaluation indexes, the operability and feasibility of indicators should be considered. For the indicators that are not operable, it can be ignored to ensure that such indicators can make the evaluation easy to implement.

(4) Principle of independence

Independence refers to the situation that the same level of evaluation indicators can not have cross effects, otherwise it will affect the weight of indicators and affect the accuracy of evaluation.

*fm15395112646@126.com, wangdandan@sina.com 


\subsection{The Construction of Evaluation Index System}

Based on the previous research results of the supplier evaluation system of fresh food supermarket, this paper constructs the evaluation index system of fresh supermarket supplier selection from four aspects: product level, service level, technology level and enterprise level. Four secondary indexes and 15 three-level indicators are selected to form the evaluation index system, as shown in Figure 1 .

(1) Product level

The quality of fresh products directly affects the quality of supermarket products, including: freshness, product quality, purchasing cost.

Product freshness is a measure of product freshness.

Product quality refers to the sum of the characteristics and characteristics of a product to meet the specified needs and potential needs. Any product is made to meet the needs of users. For product quality, whether it is a simple product or a complex product, it should be described by product quality characteristics or characteristics.

Purchasing cost refers to the logistics cost related to purchasing raw materials and components, including purchase order cost, management cost of purchasing plan making personnel, management cost of purchasing personnel, etc.

(2) Service level

As consumers, not only the pursuit of product quality, but also the demand of service level in the process of consumption, including: rapid response ability, emergency distribution ability, delivery accuracy, delivery punctuality, customer satisfaction and so on.

Rapid response capability refers to the operational capability of an enterprise to make decisions and take emergency actions quickly in order to adapt to the sudden and rapid changes of business.

Emergency distribution refers to the way of distribution in full accordance with the user's sudden distribution requirements. Emergency distribution is to supplement and improve the distribution service, and it is also the emergency capacity that distribution enterprises should have.

(3) Technical level

High quality supply chain response channels need high-level information system, logistics distribution and other equipment and facilities as guarantee, mainly including: cold chain logistics facilities and equipment, advanced level of equipment, information technology capabilities.

(4) Enterprise level

The development and innovation ability of an enterprise is the key to establish a win-win and long-term partnership, including innovation ability, leadership ability, staff quality and management level.

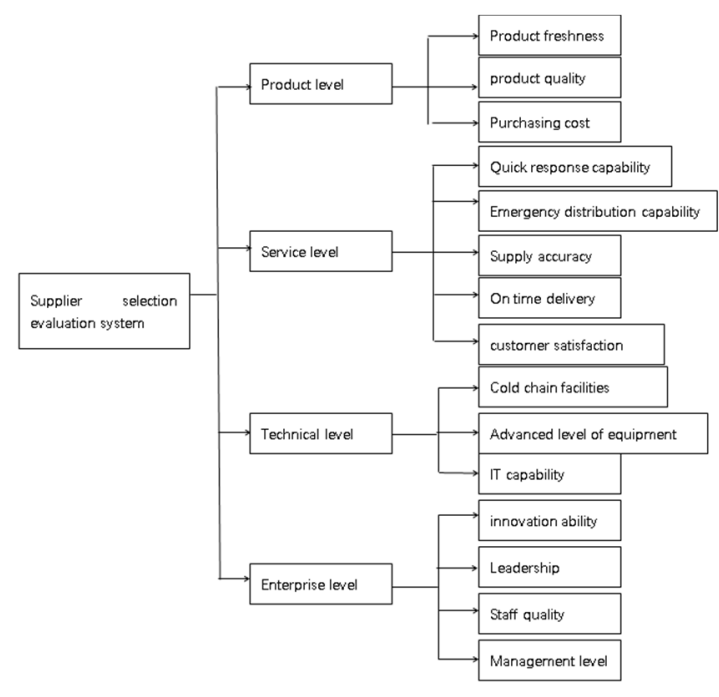

Fig 1. Evaluation index system of fresh supermarket supplier selection

Innovation ability is the ability to continuously provide new ideas, new theories, new methods and new inventions with economic value, social value and ecological value in the field of technology and various practical activities.

Leadership challenge refers to the combination of a series of behaviors. These behaviors will encourage people to follow the leader to the place they want to go, not simply obey.

The quality of staff and workers is the sum of the ideological quality, cultural and technical professional quality and physical quality of the staff working in enterprises, institutions, organs and other units according to law. Ideological quality refers to the workers' love for the motherland and the people, their sense of responsibility and enthusiasm for work, and their noble professional ethics and social morality. Cultural and technical quality refers to the level of scientific and technical knowledge, knowledge structure, technical structure, education level, working skills, skills and experience of employees. Physical fitness refers to the degree of health of employees, the ability to undertake work, the resistance to diseases, the good or bad state of mood, spirit and energy, etc.

Management ability is the general name of management power. It mainly includes the scale, quality and structure of management team, the scientific and modern degree of management means, the breadth and depth of management education, and the level of management science research and theory. The management ability of a region, a department and a country mainly depends on the quality and structure of the management team, the level of management research and education, and the modernization of management means.

\section{SUPPLIER SELECTION AND EVALUATION OF FRESH SUPERMARKET}


The Analytic hierarchy process (AHP) is an operational research theory proposed by American operations research scientist Saaty in the 1970s, and is an analytical method based on hierarchical weight decision. The analytic hierarchy process is suitable for solving the multiobjective and unstructured complex decision-making problems. The basic principle is: to hierarchical a complex problem, to make the process mathematical by using less quantitative information, to compare the indicators of the same layer by combining quantitative analysis with qualitative analysis, to establish a contrast matrix to judge its contribution rate to the previous level indicators, and so on, through Each layer carries on the comparative analysis, finally can obtain each index belongs to the weight value[3-5].

When the index weight in the evaluation model is assigned by AHP, it is divided into the following steps

(1) The hierarchical structure model is established by layering complex problems

Firstly, the related factors of complex target problems are divided into two-level and three-level indexes, which are called target layer, criterion layer and index layer respectively.

(2) Establish a comparative judgment matrix

When determining the importance of each index at each level, the uniform matrix method proposed by Saaty et al. Is used to compare the two indexes with each other, rather than comparing all the indexes together; the comparative judgment matrix is a comparison of the relative importance of the index in this layer against a certain index in the previous layer. AIJ in the comparison judgment matrix generally uses Saaty's 1-9 scale method.

(3) Calculate weight vector and check consistency

The feature vector and the maximum feature root of each contrast judgment matrix are calculated, and the consistency test is performed by using the consistency index, consistency ratio and random consistency index. If the consistency test passes, its feature vector is weight vector; if the consistency test fails, it is necessary to reestablish the contrast judgment matrix and test the consistency ratio of the matrix, and it can judge whether the weight result of the index calculated by AHP is reasonable.

(4) Calculate the weight of each indicator

There are two methods to calculate the weight of the comparison judgment matrix: sum method and root method, namely, the standard column average method and the geometric average method. In this paper, the weight value of each index is calculated by the standard column average method.

\subsection{Fuzzy Comprehensive Evaluation Method}

Fuzzy comprehensive evaluation method is a methodology put forward by American scientist Chad in the 1960s. This research method is based on some fuzzy phenomena in life that are difficult to solve with traditional precise mathematics. Its principle is to transform those qualitative evaluation indexes or factors into quantitative evaluation according to the membership principle of fuzzy mathematics, so as to solve some problems that are difficult to quantify and fuzzy uncertainty to a certain extent. The basic steps are as follows:

(1) Determine factor set

Evaluation factors refer to specific indicators and contents related to evaluation. Relatively broad and large levels can be regarded as first level evaluation indicators, and each level can be divided into specific second level evaluation indicators.

(2) Establish weight set

Generally, weight vector can be constructed by many methods, and analytic hierarchy process is commonly used. In this paper, AHP is used to determine the corresponding weight of each index.

(3) Establish evaluation set

The evaluation value is the evaluation value of the importance and the quality of the evaluation index. The evaluation scoring methods used include percentage system, total evaluation value of 1 or 1-9 ratio scale.

(4) calculate the comprehensive evaluation value

The comprehensive evaluation value can be calculated according to the hierarchy of evaluation indexes, the weighted average value can be calculated according to the weight and average value of each secondary index, and then the weighted average comprehensive evaluation value can be calculated according to the weight and average value of each primary index.

\section{CASE ANALYSIS OF SUPPLIER SELECTION AND EVALUATION}

Fresh legend supermarket is located in Hefei City, Anhui Province. Supplier a has provided fresh agricultural products for it for three years. Supplier a has more than 300 employees. The cold chain logistics facilities meet the requirements of fresh supermarket standards, and the price is more favorable. At present, fresh legend supermarket needs to make a comprehensive evaluation on the supply of fresh agricultural products of supplier a in the past year, and the evaluation results will be the main basis for whether to continue cooperation.

In order to reasonably determine the index weight, this paper selects AHP to establish the judgment matrix of each level, and calculates the results through the analytic hierarchy process software Yaahp to get the weight of all indicators, as shown in Table 1.

Table1. WEIGHT OF SUPPLIER EVALUATION INDEX

\begin{tabular}{|c|c|c|c|}
\hline Index & Weight & index & weight \\
\hline Product freshness & 0.1263 & $\begin{array}{c}\text { Cold chain } \\
\text { logistics facilities }\end{array}$ & 0.0834 \\
\hline product quality & 0.0396 & $\begin{array}{c}\text { Advanced level of } \\
\text { equipment }\end{array}$ & 0.0632 \\
\hline Purchasing cost & 0.1287 & IT capability & 0.0689 \\
\hline $\begin{array}{c}\text { Quick response } \\
\text { capability }\end{array}$ & 0.0898 & innovation ability & 0.0536 \\
\hline $\begin{array}{c}\text { Emergency } \\
\text { distribution } \\
\text { capability }\end{array}$ & 0.0712 & Leadership & 0.0446 \\
\hline Supply accuracy & 0.0635 & Staff quality & 0.0818 \\
\hline On time delivery & 0.0309 & Management level & 0.0123 \\
\hline $\begin{array}{c}\text { customer } \\
\text { satisfaction }\end{array}$ & 0.0422 & & \\
\hline
\end{tabular}


Next, the fuzzy comprehensive evaluation method is used to determine the evaluation results, and 20 fresh legend employees and special experts are invited to form an evaluation group. The evaluation values are given by the five level percentage system, which are excellent (90100 points), good (70-90 points), medium (50-70 points), average (30-50 points) and poor (0-30 points). The secondary indicators of a supplier are evaluated item by item and summarized The evaluation matrix in Table 2 is obtained, where the score value represents the number of people who choose the evaluation value.

Table2. WEIGHT COMPREHENSIVE SCORE OF EVALUATION SPECIALTY

\begin{tabular}{|c|c|c|c|c|c|}
\hline $\begin{array}{l}\text { Secondary } \\
\text { indicators }\end{array}$ & excellent & good & secondary & common & Poor \\
\hline $\begin{array}{c}\text { Product } \\
\text { freshness }\end{array}$ & 8 & 5 & 4 & 2 & 1 \\
\hline $\begin{array}{l}\text { product } \\
\text { quality }\end{array}$ & 6 & 7 & 4 & 2 & 1 \\
\hline $\begin{array}{l}\text { Purchasing } \\
\text { cost }\end{array}$ & 2 & 2 & 9 & 5 & 2 \\
\hline $\begin{array}{c}\text { Quick response } \\
\text { capability }\end{array}$ & 0 & 1 & 2 & 8 & 9 \\
\hline $\begin{array}{c}\text { Emergency distribution } \\
\text { capability }\end{array}$ & 3 & 3 & 5 & 6 & 3 \\
\hline $\begin{array}{c}\text { Supply } \\
\text { accuracy }\end{array}$ & 2 & 3 & 7 & 3 & 5 \\
\hline $\begin{array}{l}\text { On time } \\
\text { delivery }\end{array}$ & 2 & 4 & 7 & 6 & 1 \\
\hline $\begin{array}{c}\text { customer } \\
\text { satisfaction }\end{array}$ & 3 & 2 & 4 & 7 & 4 \\
\hline $\begin{array}{c}\text { Cold chain } \\
\text { logistics facilities }\end{array}$ & 0 & 2 & 2 & 11 & 5 \\
\hline $\begin{array}{c}\text { Advanced level } \\
\text { of equipment }\end{array}$ & 2 & 5 & 3 & 9 & 1 \\
\hline IT capability & 0 & 1 & 7 & 6 & 6 \\
\hline $\begin{array}{c}\text { innovation } \\
\text { ability }\end{array}$ & 1 & 4 & 3 & 4 & 8 \\
\hline Leadership & 2 & 2 & 8 & 7 & 1 \\
\hline $\begin{array}{c}\text { Staff } \\
\text { quality }\end{array}$ & 1 & 5 & 5 & 4 & 5 \\
\hline $\begin{array}{l}\text { Management } \\
\text { level }\end{array}$ & 3 & 2 & 6 & 7 & 2 \\
\hline
\end{tabular}

The score of each evaluation grade is set as excellent 100, good 80, medium 60, general 40 and poor 20. Multiply and add the score of the first 20 personnel with the specific score, and then average it to 100. Multiply and add it with the weight of each index to get the evaluation result of 49.19. The evaluation result of supplier a is general. According to the evaluation results in Table 2, it is not difficult to see that the weight of quick response capability and cold chain facilities is relatively high, but the excellent proportion in the evaluation is low, indicating that suppliers need to increase the improvement of quick response capability and cold chain logistics facilities and equipment in the next step.

\section{CONCLUSION}

Based on the existing fresh supermarket supplier data characteristics and evaluation needs, this paper selects a total of 15 specific index factors, and establishes the supplier selection evaluation model; through the application of AHP and fuzzy comprehensive evaluation method, this paper evaluates the a supplier of Hefei fresh legend supermarket in Anhui Province; according to the evaluation results, this paper gives specific suggestions for improving the service ability of a supplier Suggestions.

\section{ACKNOWLEDGEMENT}

This work was supported by Anhui Xinhua university Comprehensive reform pilot project of logistics management under Grant No.2016zy068 and 2018 university level scientific research project of Quality Education Research Center for college students of Anhui Xinhua University under Grant No.IFQE201819 and 2019 Anhui University Humanities and social sciences research project under Grant No.SK2019A0728. The corresponding author of the article is Wang Dan-dan.

\section{REFENCES}

1. Li Pengwei. Fresh food supply chain ushers in a new era of global development opportunities. Modern logistics news, February 28, 2018

2. Zhang Yujie. Research on cold chain logistics optimization of fresh food in chain supermarkets[J]. Education and teaching forum, 2013, 52 (6): 147-148 
3. Chen Miaojin. Supplier selection evaluation based on AHP [J]. Economic and trade practice, 2016,24 (19): 123-124

4. Wang Yasai. Selection and evaluation of fresh food suppliers[J]. Logistics engineering and management, 2016, 12 (7): 175-176

5. $\mathrm{Xu}$ Zhiwei. Application of $\mathrm{ABC}$ in supplier evaluation[J]. Shanghai automobile, 2013, (6): 3234 